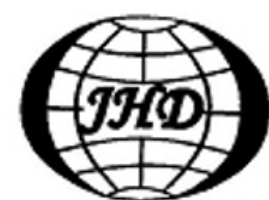

www.sciencedirect.com/ science/journal/10016058

\title{
OVERVIEW OF THE 5TH INTERNATIONAL CONFERENCE ON ASIAN AND PACIFIC COASTS
}

\author{
LU Dong-qiang \\ Shanghai Institute of Applied Mathematics and Mechanics, Shanghai University, Shanghai 200072, China, \\ E-mail: dqlu@shu.edu.cn
}

The 5th International Conference on Asian and Pacific Coasts (APAC-2009) was held in the Nanyang Technological University (NTU), Singapore from 13 to 16 October, 2009. This conference was jointly organized by the Chinese Ocean Engineering Society, the Coastal Engineering Committee of Japan Society of Civil Engineers, the Korean Society of Coastal and Ocean Engineers, and the Maritime Research Center at $\mathrm{NTU}^{[1]} .227$ delegates from 18 countries, including China, Japan, Korea, USA, The Netherlands, India, Indonesia, Singapore, Vietnam, UK, Afghanistan, Iran, etc., attended the conference.

Five keynote lectures and more than 180 papers in 31 parallel technical sessions were presented at the conference. The speakers and titles of the five keynotes are listed as follows:

(1) Chiang C. Mei (Massachusetts Institute of Technology, USA): Hydrodynamics of Two Devices for Wave-Power Extraction.

(2) Joseph H. W. Lee (The University of Hong Kong, China): Forecasting of Coastal Algal Blooms - A Hydraulic Engineering Perspective.

(3) Byung Ho Choi (Sungkyunkwan University, Korea): Construction Status of Sihwa Lake Tidal Power Plant Project.

(4) Kazuo Nadaoka (Tokyo Institute of Technology, Japan): Reef Connectivity - A Key Factor Governing Resilience of Coastal Ecosystems.

(5) Jian-Hua Tao (Tianjin University, China): Simulation of Eco-Environment for Coastal Water of Bohai.

The proceedings ( 4 volumes with $\mathrm{CD}$ ), edited by Soon Keat Tan and Zhenhua Huang and published by the World Scientific, collect 186 technical papers presented at the APAC-2009 and cover a wide range of topics, including "coastal and harbor structures, sediment processes and shoreline changes, coastal environmental problems and marine ecology, coastal zone management and planning, tsunami, ocean energy, global environmental problems, laboratory and field measurement techniques, numerical simulations of coastal problems, and basic research in ocean waves, currents, and tides" ${ }^{[2]}$.

The first APAC, held at Dalian University of Technology, China, in 2001, was initiated by Professors Da-hong Qiu, Shi-leng Xie, Yoshimi Goda, and Byung Ho Choi, and the late Professor Guo-ren Dou. Since its inception, the APAC series had been successively held in Chiba, Japan (2004), Jeju, Korea (2005) and Nanjing, China (2007). According to APAC announcements, the purposes of the APAC conferences are to "(1) promote technological progress and activities, international technological transfer and cooperation, and opportunities for engineers and researchers to maintain and improve scientific and technical competence, (2) provide a timely international forum for academic and technical activities, cooperation, opportunity and fellowship among researchers and engineers, and (3) provide a special chance for exchanging experience of coastal and port engineering development among Asian and Pacific countries and regions and promoting scientific and technological cooperation among Asian countries and regions" $"[1]$.

The 6th International Conference on Asian and Pacific Coasts (APAC-2011) will be held in Hong Kong, China, from 14 to 16 December, 2011. The Chair and Secretary General of the Local Organizing Committee are, respectively, Prof. Joseph H. W. Lee and Dr. Chiu-On Ng, both from The University of Hong Kong, China.

\footnotetext{
References

[1] http://www.apac2009.org

[2] TAN Soon Keat and HUANG Zhenhua (Eds.), Proceedings of the 5th International Conference on Asian and Pacific Coasts. 4 Volumes with CD, Singapore: World Scientific Publishing, 2009.
} 